\title{
Rational Design and Testing of Anti-Knock Additives
}

\author{
Andrew D. Ure ${ }^{1, *}$, Manik K. Ghosh ${ }^{1}$, Maria Rappo ${ }^{2}$, Roland Dauphin ${ }^{2}$ and Stephen Dooley ${ }^{1}$ \\ 1 School of Physics, The University of Dublin, Trinity College, Dublin 2, Ireland; ghoshm@tcd.ie (M.K.G.); \\ stephen.dooley@tcd.ie (S.D.) \\ 2 Total Marketing Services, Centre de Recherche de Solaize, Chemin du Canal, 69360 Solaize, France; \\ maria.rappo@total.com (M.R.); roland.dauphin@total.com (R.D.) \\ * Correspondence: aure@tcd.ie
}

Received: 13 August 2020; Accepted: 14 September 2020; Published: 19 September 2020

\begin{abstract}
An innovative and informed methodology for the rational design and testing of anti-knock additives is reported. Interaction of the additives with $\mathrm{OH}^{\bullet}$ and $\mathrm{HO}_{2}{ }^{\bullet}$ is identified as the key reaction pathway by which non-metallic anti-knock additives are proposed to operate. Based on this mechanism, a set of generic design criteria for anti-knock additives is outlined. It is suggested that these additives should contain a weak X-H bond and form stable radical species after hydrogen atom abstraction. A set of molecular structural, thermodynamic, and kinetic quantities that pertain to the propensity of the additive to inhibit knock by this mechanism are identified and determined for a set of 12 phenolic model compounds. The series of structural analogues was carefully selected such that the physical thermodynamic and kinetic quantities could be systematically varied. The efficacy of these molecules as anti-knock additives was demonstrated through the determination of the research octane number (RON) and the derived cetane number(DCN), measured using an ignition quality tester (IQT), of a RON 95 gasoline treated with 1 mole \% of the additive. The use of the IQT allows the anti-knock properties of potential additives to be studied on one tenth of the scale, compared to the analogous RON measurement. Using multiple linear regression, the relationship between DCN/RON and the theoretically determined quantities is studied. The overall methodology reported is proposed as an informed alternative to the non-directed experimental screening approach typically adopted in the development of fuel additives.
\end{abstract}

Keywords: anti-knock; phenol; ignition quality tester; fuel additives

\section{Introduction}

Over the past 30 years, concerns over anthropogenic greenhouse gas emissions have driven the need for new, more efficient combustion technologies for transportation [1]. To facilitate this, some legislative bodies, such as the European Commission, have introduced stringent emissions standards (e.g., Euro 6) [2] as well as directives that mandate introduction of alternative fuels [3]. Throughout this period, the chemical composition of fossil-derived liquid transportation fuels has remained relatively constant and alternative fuels have not been widely adopted. Thus, any gains in efficiency have generally been achieved through incremental increases in efficiency of existing powertrains (e.g., spark-ignition and compression ignition engines) as opposed to changes to the fuel [1].

Finished fuels are the result of refining processes which ensure that the fuel conforms to the legislated chemical and physical property specifications required for the market. These fuel specifications have remained largely unchanged for a number of years and the associated refinement processes are well established. Consequently, amendments and additions to the refinement process often have large associated development and capital costs. Alternatively, physical and chemical 
properties of fuels can be tailored through the addition of fuel additive packages-to bring the specification of the "non-compliant" fuel up to the required standard. Additives are routinely blended into commercial fuels and include anti-knock additives (see below), cetane boosters, deposit control additives, anti-statics, drag reducing agents, and friction modifiers [4]. The development of effective drop-in fuel additives offers a viable route to circumvent some limitations imposed on the chemical or physical properties of a fuel by the refinement process.

Since the 1970s, the research octane number (RON) of a typical gasoline has plateaued [1]. This is problematic because higher octane gasolines have a number of economic and environmental benefits [5]. For example, tank-to-wheel efficiency has been directly correlated to the RON of the gasoline, i.e., increasing the $\mathrm{RON}$ decreases $\mathrm{CO}_{2}$ emissions-provided the operating conditions of the engine allow the increase in RON to be utilized [5]. Similarly, many higher efficiency spark ignition combustion technologies are knock-limited as a result of this upper ceiling on the RON (see below) [1]. Therefore, the ability to conveniently increase the RON of a fuel is highly desirable-both economically and environmentally.

In addition to fossil-derived fuels, as alternative fuels are mandated to be blended with fossil-derived fuels in increasing fractions, the chemical structure and consequently the physical properties of the resulting fuel will deviate markedly from those encountered at present. This is because the chemical structure of alternative, biologically derived fuels differs significantly from that of fossil derived fuels, e.g., the presence of a large fraction of oxygenated molecules in gasolines/diesels [6]. Therefore, fuel additives are set to play an increasingly prevalent role in facilitating the transition of the global transportation fleet to alternative fuels because they offer a convenient means by which to bring alternative fuel blends within specification.

The development of fuel additives typically involves the undirected screening of a library of candidate molecules and measuring their effect on a desired property. While this methodology has proved successful in the past, most notably with the discovery of tetra ethyl lead, it is inherently reliant on inefficient experimental testing programs [7]. This necessitates that any new additive candidate must be both available in sufficient quantities and affordable. This is limiting in any cases where the additive is a product of synthetic chemistry research and development and/or relatively large quantities are required for the test (see below), i.e., these factors inhibit the rational design of new fuel additives. Additive development methodologies that do not require significant experimental undertakings hold a significant advantage in this regard.

In this paper, using knock as a case study, we describe our progress in creating a refined, small-scale, additive design/testing methodology which can resolve this impasse. The methodology couples two components:

1. Additive design using molecular thermodynamics from theory.

2. Additive testing using small scale ignition measurements.

To identify molecular thermodynamic properties pertinent to knock, it is first necessary to consider the chemical origins of knock and the postulated mechanisms of existing anti-knock additives.

\subsection{Knock in Spark Ignition (SI) Engines}

Knock is a phenomenon that occurs in spark ignition engines as a result of autoignition of the end-gas ahead of the flame front [8,9]. This autoignition is caused by the compression of the end-gas by the piston, the compression heating effect of the burned gas, and the propagating flame [8]. After autoignition, a large pressure increase occurs, followed by pressure oscillations as the pressure waves reflect off the cylinder walls. These pressure oscillations are capable of causing damage to the engine, and therefore knock is an extremely problematic phenomenon in spark ignition engines.

The occurrence of knock is governed by the cylinder design, engine operating conditions, and the chemical composition of the fuel. Mechanical causes of knock, i.e., cylinder design and engine operating conditions can, to an extent, be mitigated by engineering solutions, i.e., knock sensors 
and accompanying control systems-at the expense of reduced engine performance and efficiency. However, inhibition of knock in this manner is not always possible. For example, in spark ignition engines, the occurrence of knock limits access to higher compression ratios or boosted intake pressures through turbo charging that would allow for increased thermal efficiency. Similarly, homogeneous charge compression ignition engines are prone to knocking in the SI mode at high load [10]. This is because under these respective operating conditions, the chemical composition of a typical commercial gasoline renders it prone to knock $[8,10]$. Thus, the propensity of a fuel to knock is fundamentally limiting to engine efficiency.

\subsubsection{Quantifying Knock—Research Octane Number (RON)}

The propensity of a gasoline to resist knock is most commonly measured by its research octane number (RON). The RON is determined using a Cooperative Fuel Research (CFR) engine according to ASTM D 2699 [11]. The CFR engine is a single-cylinder, four-stroke engine with a variable compression ratio. Approximately $500 \mathrm{~mL}$ of fuel is required per test. Heaters control the temperature of inlet air and of the air/fuel mixture, while gauges monitor the engine operation and detect the occurrence of detonations. To perform the RON tests, the engine speed is set to $600 \mathrm{rpm}$, the inlet air temperature is adapted depending on the barometric pressure, and the ignition timing is fixed regardless the compression ratio [11]. The RON of a tested fuel is defined as the point at which the occurrence of knock is equivalent to a blend of $n$-heptane and 2,2,4-trimethylpentane (also known as iso-octane, hence the name of this scale); where the RON value itself is defined as the volumetric percentage of 2,2,4-trimethylpentane in the mixture. A higher measured value of RON indicates a greater propensity for the fuel to resist knock. Based on these test conditions, two important points should be noted:

1. Determination of the RON requires a relatively large volume of fuel. This can be restrictive to the testing of new fuel additives (see below).

2. The compression ratio of a given RON test is dependent on the propensity of the test fuel to resist knock. Fuels more resistant to knock will require higher compression ratios, and thus experience higher end-gas temperatures and pressures. The temperature and pressure trajectories define the reaction rate of the flame and the end gas. This makes it difficult to objectively interpret the underlying chemistry contributing to any observed change in the RON.

\subsubsection{The Chemical Causes of Knock}

To prevent knock, the end-gas must be prevented from autoigniting. Thus, at source, knock is a purely chemical phenomenon. The two $\mathrm{HO}^{\bullet}$, formed in Reaction 2, are ultimately the chemical cause of knock. They react bimolecularly to form $\mathrm{H}_{2} \mathrm{O}$. This reaction is highly exothermic and raises the temperature of the end-gas, causing autoignition. Westbrook et al. showed how this can be related to octane number [12]. The oxidation of a range of primary reference fuels ( $n$-heptane and iso-octane) under knocking conditions was studied [12]. It was shown that the rate of production of $\mathrm{HO}^{\bullet}$ radicals decreased with increasing RON. Reactions 1 and 2 were identified as the reactions with the largest sensitivity coefficients in the oxidation of $n$-heptane and iso-octane at $800 \mathrm{~K}$ [12]:

$$
\begin{gathered}
\mathrm{HO}_{2}{ }^{\bullet}+\mathrm{HO}_{2} \bullet-\mathrm{H}_{2} \mathrm{O}_{2}+\mathrm{O}_{2} \\
\mathrm{H}_{2} \mathrm{O}_{2}+\mathrm{M} \longrightarrow 2 \mathrm{HO}^{\bullet}+\mathrm{M}
\end{gathered}
$$

Thus, if the chemical structure of a fuel facilitates the formation of $\mathrm{HO}_{2}{ }^{\bullet}$, and consequently $\mathrm{HO}^{\bullet}$, it is more prone to knock. For example, in $n$-heptane there are many facile pathways for isomerization reactions following hydrogen atom abstraction, which lead to the formation of $\mathrm{HO}_{2}{ }^{\bullet}$ and $\mathrm{HO}^{\bullet}$ more readily than in iso-octane, where there are few isomerization pathways below $1000 \mathrm{~K}$. Thus, $n$-heptane $(\mathrm{RON}=0)$ is more prone to knock than iso-octane $(\mathrm{RON}=100)$. It follows that if $\mathrm{HO}_{2}{ }^{\bullet}$ and $/$ or $\mathrm{HO}^{\bullet}$ can be removed from the radical pool, the rates of formation of $\mathrm{HO}^{\bullet}$ will be lower, and the knock resistance of the fuel will be increased. 
In practical gasolines, Reactions 1 and 2 have historically been inhibited by the addition of anti-knock fuel additives and/or improved refinement processes. The latter was a result of the implementation of catalytic cracking and platinum reforming [1], which increased the content of iso-paraffins and aromatics, respectively (i.e., components with limited isomerization pathways), of gasoline. The former warrants a more detailed discussion.

\subsection{Anti-Knock Additives}

\subsubsection{Metallic Anti-Knock Additives}

Metallic anti-knock additives (Figure 1), most notably tetraethyl lead (TEL) but also methylcyclopentadienyl manganese tricarbonyl [13] and ferrocene [14], were highly prevalent in commercial gasolines from the 1930s to the mid-1980s. These additives are highly effective at reducing the propensity of a fuel to exhibit knock when added to the fuel in small amounts. For example, TEL was added to commercial gasoline at a treatment rate of $0.8 \mathrm{~g} \mathrm{~L}^{-1}(0.02 \mathrm{~mole} \%$, assuming a gasoline molecular weight of $100 \mathrm{~g} \mathrm{~mol}^{-1}$ ) [12].

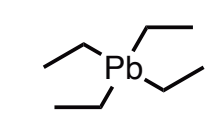

Tetraethyl lead

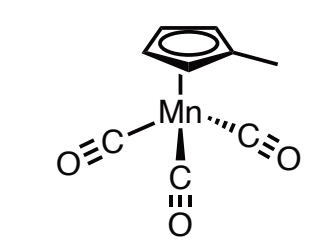

Methylcyclopentadienyl manganese tricarbonyl

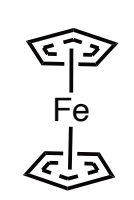

Ferrocene

Figure 1. Chemical structures of the metallic anti-knock additives: tetraethyl lead (TEL), methylcyclopentadienyl manganese tricarbonyl, and ferrocene.

TEL is the most comprehensively studied metallic anti-knock additive. However, the precise manner in which TEL inhibits knock has been subject to much debate and, at the time of writing, remains unresolved. This is primarily due to the fact that TEL was phased out of use due to its toxicity and incompatibility with exhaust gas treatment systems [15]; a fact that was foreseen by Ballinger and Rayson as early as 1971 [16]. A general consensus on the chemical kinetic pathway by which TEL inhibits knock was reached (see below); however, experimental evidence on the physical form of the lead species responsible for knock inhibition gave rise to two competing theories.

Norrish and co-workers used flash photolysis to study the effect of TEL on the reaction of amyl nitrate, acetylene, and oxygen [17] at low pressure $(\sim 0.01-0.03 \mathrm{~atm})$ in a static system. It was shown that addition of TEL to the sensitizer/fuel mixture caused a lengthening of the ignition delay. A band attributed to gaseous $\mathrm{PbO}$ was observed in the emission spectrum when the reaction was carried out in the presence of TEL. Simultaneously, a reduction in intensity of the $\mathrm{HO}^{\bullet}$ emission spectra was noted, compared to the system in the absence of TEL. No evidence for the presence of solid $\mathrm{PbO}$ was found. Analogous results were observed when acetylene was replaced for $n$-heptane or iso-octane [18]. Based on these observations, Norrish concluded that the active anti-knock was gaseous $\mathrm{PbO}$ and that it was effective because it reduced the concentration of $\mathrm{HO}^{\bullet}$ radicals present in the end-gas, preventing autoignition. A precise mechanism for the reduction in $\mathrm{HO}^{\bullet}$ concentration was not evaluated. It should be noted that the use of low pressures and a photo-initiator are significantly different reaction conditions to those experienced in-engine. To the best of our knowledge, no attempt has been made to support these claims through engine studies. Therefore, they should be interpreted in the context of knock with appropriate caution.

Independently, Benson later provided a series of thermodynamic and kinetic arguments in support of the following chain debranching, gas-phase mechanism [19].

$$
\mathrm{Pb}+\mathrm{HO}_{2}^{\bullet} \longrightarrow \mathrm{PbO}+\mathrm{HO}^{\bullet}
$$




$$
\begin{gathered}
\mathrm{PbO}+\mathrm{HO}_{2} \bullet \longrightarrow \mathrm{PbOH}+\mathrm{O}_{2} \\
\mathrm{PbOH}+\mathrm{HO}_{2} \bullet \longrightarrow \mathrm{Pb}+\mathrm{O}_{2}+\mathrm{H}_{2} \mathrm{O} \\
\mathrm{Net}: 3 \mathrm{HO}_{2} \longrightarrow \mathrm{HO}^{\bullet}+2 \mathrm{O}_{2}+\mathrm{H}_{2} \mathrm{O}
\end{gathered}
$$

In this process, three radicals are converted to one, reducing the radical population while regenerating the initial lead species. The fact that lead reacts catalytically is assumed on the basis it is only required in trace amounts $\left(\sim 10^{-6} \mathrm{M}\right.$ in an average compression stroke) to have a significant inhibitive effect on knock [18]. Benson proposes that the lead reacts with $\mathrm{HO}_{2}{ }^{\bullet}$, rather than $\mathrm{HO}^{\bullet}$ on the basis that $\mathrm{HO}_{2}$ 'is less reactive.

In order for this cycle to be effective, the rate constant of reactions 3-5 would need to be much greater than that of Reaction 1. Benson estimates that each of these reactions have a rate constant of at least $1 \times 10^{9.5} \mathrm{~L} \mathrm{~mol}^{-1} \mathrm{~s}^{-1}$ at $\mathrm{T}>800 \mathrm{~K}$. However, as Reaction 1 is known to have a rate constant close to the collisional limit $\left(1 \times 10^{14} \mathrm{~s}^{-1}\right)$, this chain debranching mechanism is unlikely based on simple kinetic considerations. Additionally, Benson's primary argument for the homogeneous nature of the catalyst is that a heterogeneous $\mathrm{PbO}$ catalyst is coordinatively saturated. This fails to account for any redox activity of the $\mathrm{Pb}$ atom and is true only so long as $\mathrm{Pb}$ remains in the $2+$ oxidation state. Should the $\mathrm{Pb}$ be oxidized to $\mathrm{Pb}(\mathrm{IV})$, the $\mathrm{Pb}$ atom is no longer coordinatively saturated.

Walsh and co-workers have proposed an alternative mechanism [20]. The effect of TEL on the ignition of diethyl and diisopropyl ether at 633 and $483 \mathrm{~K}$, at $0.1 \mathrm{~atm}$ was investigated. These temperatures were selected as being representative of the high and low temperature oxidation regimes, respectively. It was found that TEL had no effect on the induction time before the observance of a cool flame. The increase in pressure observed at the onset of the cool flame was reduced in the presence of TEL and the rate of reaction at high temperatures was significantly lowered. Analogous observations were made for methane [21]. In addition, it was shown that TEL is an effective anti-knock in engines running on either formaldehyde or hydrogen. On this basis, it was speculated that TEL is likely to affect the destruction of the chain branching $\mathrm{H}_{\text {or }} \mathrm{HO}_{2} \bullet$ radicals [20]. Subsequently, Salooja has studied the effect of both TEL and $\mathrm{PbO}$ on the oxidation of $n$-hexane [22,23]. It was shown that the addition of $\mathrm{PbO}$ inhibited the formation of organic peroxides and $\mathrm{H}_{2} \mathrm{O}_{2}$ at low and high temperatures, respectively. Similar results had previously been reported by Sturgis et al. [24].

Walsh observed the formation of a "fog" or "smoke" of what was postulated to be $\mathrm{PbO}$ in the course of his experiments [20]. It was shown that this smoke formed a PbO film on the surface of the reaction vessel which gave rise to the same inhibitive effect as TEL. It was suggested that the inhibition of ignition observed in the presence of $\mathrm{PbO}$ was caused by the destruction of chain branching radicals on the PbO-coated reactor walls. Walsh noted that this surface effect was unlikely to be the mode of action of TEL in-cylinder, as the pressure is too high to allow for diffusion of reactive radical species to the cylinder wall [25], and postulated that a colloidal dispersion of $\mathrm{PbO}$ may form during the compression stroke [20]. Subsequent work in-engine using light scattering experiments [26] and exhaust gas sampling coupled with X-ray diffraction [27] provided evidence for the formation of a colloidal dispersion of $\mathrm{PbO}$ during the compression stroke, with an average particle size of $<100 \AA$.

More recently, Fenard et al. have studied the anti-knock effect of ferrocene on iso-octane and 3-hexene in a rapid compression machine [14]. It was shown that the addition of ferrocene lengthened the ignition delay of these fuels. It was proposed that the mechanism of action was similar to that which has been suggested for tetraethyl lead i.e., $\mathrm{FeO}$ particles are responsible for an accelerated rate of consumption of $\mathrm{HO}_{2}{ }^{\bullet}$ radicals by a heterogeneous catalytic process, thus preventing radical chain branching and lowering the reaction rate.

In summary, the evidence for either the homogeneous or heterogeneous mechanisms of action of TEL are far from conclusive. The majority of studies on the topic have been related to ignition and conducted at conditions that are not representative of those found in-engine, in particular at low pressure. Therefore, any supposition of these results towards knock should be tentative. Nonetheless, it is universally accepted that $\mathrm{PbO}$ is the active form of the additive and that TEL (and other metallic 
additives) prevent autoignition by catalyzing the conversion of $\mathrm{HO}_{2}{ }^{\bullet}$ to less reactive species than $\mathrm{H}_{2} \mathrm{O}_{2}$. Thus, the TEL reaction mechanism is in direct competition with Reaction 1 and any effect of TEL on the rate of Reaction 2 is assumed to be indirect. Competition with Reaction 1 rather than Reaction 2 occurs because $\mathrm{HO}_{2}{ }^{\bullet}$ is less reactive than $\mathrm{HO}^{\bullet}$, and therefore $\mathrm{HO}_{2}{ }^{\bullet}$ has a longer lifetime and a higher probability to interact with TEL compared to $\mathrm{HO}^{\bullet}$. Finally, metallic additives have been shown generally to have little effect on the first stage of ignition. This is likely a result of the fact that the gaseous metal oxides postulated as key reactive intermediates are only formed at higher temperatures [14].

\subsubsection{Non-Metallic Anti-Knock Additives}

It is important to make a distinction between an anti-knock additive and an octane-boosting fuel component. Octane boosters are typically added to fuels in large quantities. Alcohols [28], ethers [29-31], levulinate esters [32-34], and aromatic hydrocarbons [35-37] have all been demonstrated as octane boosters. The common feature of these molecule classes is that individually they have a high octane number. This is a consequence of the inability of these molecules to undergo low temperature oxidation and therefore these molecules do not branch the radical chain (although they may propagate it), and thus they raise the RON [38]. Octane boosters should be considered fuel components in their own right. In contrast, anti-knock additives should be effective when added at $<5 \mathrm{~mol} \%$.

Literature reports of non-metallic anti-knock additives are relatively scarce and, to the best of our knowledge, are reviewed here to their entirety. Brown and co-workers have shown that aniline and 103 of its derivatives are effective as anti-knock additives [39]. It was shown that the presence of a N-H hydrogen atom in the additive was essential to the inhibition of knock. On this basis, Brown suggested that the $\mathrm{N}-\mathrm{H}$ atom in these anilines was abstracted by a reactive radical species $\left(\mathrm{HO}_{2}{ }^{\bullet}\right.$ or $\mathrm{HO}^{\bullet}$ ). Importantly, the resulting anilino radical is stabilized by both delocalization throughout the conjugated aromatic system and via the inductive effect by alkyl groups in any of the N-, 2-, 4-, or 6-positions. Thus, hydrogen atom abstraction from the aniline by the reactive radical yields a more thermodynamically stable radical. The anilino radial can be considered a thermodynamic sink for reactive radical species. In this way, the proposed mechanism of action of non-metallic anti-knock additives proposed by Brown is analogous to that for the metallic additives. Brown suggests that non-metallic anti-knock additives operate in the low temperature regime, in contrast to metallic additives discussed above. This claim is supported by a rapid compression machine study by Mohamed [40]. It was shown that the addition of 5 mole $\%$ diethylamine to $n$-pentane and $n$-heptane retarded the ignition delay of both fuels. At $\mathrm{T}_{\mathrm{c}}>850 \mathrm{~K}$, addition of diethylamine showed no effect on the ignition delay of $n$-pentane. It was suggested that this was due to the absence of low-temperature reactivity for $n$-pentane under these conditions. This was supported by the fact that an inhibitive effect on autoignition was observed for $n$-heptane, which does display low temperature reactivity at $\mathrm{T}_{\mathrm{c}}>850 \mathrm{~K}$. Thus, while the proposed mechanisms of metallic and non-metallic anti-knock additives are comparable, the temperature regimes in which they appear to operate are not.

Halstead studied the effect of $N$-methyl aniline and 6-methyl-1,2,3,4-tetrahydroquinoline on the autoignition of 2-methylpentane, $n$-hexane, and methyl cyclohexane using a rapid compression machine [41] at $20 \mathrm{bar}, 720 \mathrm{~K}$. Both additives were found to have a comparable molar effectiveness in lengthening ignition delay time. This was interpreted as both of these additives operating by the same reaction mechanism. The inhibition by the $N$-methyl aniline and 6-methyl-1,2,3,4-tetrahydroquinoline was also found to be similar to that of $\mathrm{H}_{2}$ and $\mathrm{CO}$. By comparing the magnitude and temperature dependence of the experiments using $\mathrm{H}_{2}$ and $\mathrm{CO}$ as inhibitors with previously published reaction rates for these molecules with $\mathrm{HO}^{\bullet}$, Halstead concluded that $N$-methyl aniline and 6-methyl-1,2,3,4-tetrahydroquinoline inhibited knock through reaction with $\mathrm{HO}^{\bullet}$ [41].

Comprehensive details on the absolute effect of anilines on RON are conspicuously absent from the literature; most likely this is a result of the proprietary nature of the data. However, Bradley notes 
that $0.6 \mathrm{mmol} \mathrm{L}^{-1}$ of TEL can raise the octane level of a paraffinic fuel by 3 numbers, while $90 \mathrm{mmol} \mathrm{L}^{-1}$ of $N$-methylaniline are required to have the same effect [14]. This is a 150-fold difference in molar effectiveness. This is compelling evidence that lead additives act catalytically, and each lead atom is able to consume multiple radicals. An alternative explanation to this observation may be that the lead based additives are not restricted to reacting with only $\mathrm{HO}^{\bullet}$ and $\mathrm{HO}_{2}{ }^{\bullet}$ whereas non-metallic additives are, because the radical must be reactive enough to first abstract a hydrogen atom from the additive molecule [14].

Phenols are also able to act as anti-knock additives. Recently, Zhang and co-workers investigated the potential anti-knocking effect of a series of six phenols using a combination of detailed chemical kinetic models and experimental measurements [42]. The reaction mechanism generator was used to produce a combined kinetic model for the six phenols. The thermochemistry for the phenols in these models was estimated using group additivity while kinetic parameters were derived from mapping rate rules or by training reactions from the reaction mechanism generator database. Engine-like simulations on $n$-butane treated with 2 mole $\%$ additive were performed in a closed adiabatic homogeneous batch reactor with a volume history derived from the pressure profile of a real CFR engine test. The resulting ignition timings were compared with those of primary reference fuels and used to estimate the change $(\Delta)$ in RON. The predicted $\Delta$ RONs were compared with experimental measurements on a RON $\sim 96$ gasoline treated with $20 \mathrm{~g} \mathrm{~L}^{-1}(\sim 2.5$ mole \%) of each additive. The effect on the RON was typically underpredicted by the simulation, by an average of 0.5 octane numbers. It is difficult to distinguish if this is a result of experimental uncertainty, the model itself, the fact that different fuels were tested in each case ( $n$-butane vs. gasoline), or the fact that the simulations and experiments were performed at different treatment rates. Nonetheless, the experimental RON measurements showed that these additives generally increase the octane number of the fuel by up to 1.7 for 2,4-dimethylphenol [42].

The anti-knock effect was attributed to the consumption of reactive radical species by the phenol, in a similar mechanism to that followed by the anilines. The chemical kinetic models generated suggest that the reaction proceeds via an initial hydrogen atom abstraction step to give either the O-centered (methylphenoxyl) or the methyl-centered (hydroxybenzyl) radical, consuming one $\mathrm{HO}^{\bullet}$ or $\mathrm{HO}_{2}{ }^{\bullet}$ radical. It was proposed that the methylphenoxyl and hydroxybenzyl radicals then consume a second $\mathrm{HO}^{\bullet}$ or $\mathrm{HO}_{2}{ }^{\bullet}$ radical, via a disproportionation reaction, to give a neutral product (a quinone-methide). Overall, one phenol molecule was proposed to consume two radicals to give a neutral product. Thus, the additive provides a thermodynamic sink for $\mathrm{HO}^{\bullet}$ and $/$ or $\mathrm{HO}_{2}{ }^{\bullet}$.

Interestingly, Walsh has curated a "considerable mass of previously incoherent data" [37] which demonstrates that substituted benzenes can also act as anti-knock additives. Of those reported, 1,3,5-trimethyl benzene was found to be the most effective. Although it is only $~ 30 \%$ as effective as aniline, it is $\sim 66 \%$ as effective as phenol. Walsh establishes the following hierarchy based on this data: anilines $>>$ phenols $>$ benzenes. It is noted that aromatic substituents in the 2, 4, and 6 positions are preferable over those in the 3 and 5 positions, as these lead to the formation of more stable radical species. Furthermore, the presence of substituents that are able to undergo beta-scission is shown to promote knock [37].

$$
\begin{gathered}
\mathrm{XH}+\mathrm{HO}_{2}{ }^{\bullet} \longrightarrow \mathrm{X}^{\bullet}+\mathrm{H}_{2} \mathrm{O}_{2} \\
\mathrm{XH}+\mathrm{HO}^{\bullet} \longrightarrow \mathrm{X}^{\bullet}+\mathrm{H}_{2} \mathrm{O} \\
\mathrm{X}^{\bullet}+\mathrm{Y} \longrightarrow \text { Active Radicals }
\end{gathered}
$$

Based on these literature reports, it is apparent that non-metallic anti-knock additives prevent autoignition by interacting with $\mathrm{HO}_{2}{ }^{\bullet}$ and $\mathrm{HO}^{\bullet}$ according to Reactions 7 and/or 8 . In order for Reactions 7 or 8 to be kinetically and thermodynamically favorable, the additive must possess a hydrogen atom that is readily abstracted, i.e., the $\mathrm{X}-\mathrm{H}$ bond dissociation energy must be as low as possible. Furthermore, in order to act as a thermodynamic sink for $\mathrm{HO}_{2}{ }^{\bullet}$ and $\mathrm{HO}^{\bullet}, \mathrm{X}^{\bullet}$ must be stable, so as to be non-propagating and non-branching. This also somewhat mitigates the fact that $\mathrm{H}_{2} \mathrm{O}_{2}$ 
is formed by Reaction 7, as the formation of $\mathrm{X}^{\bullet}$ is preferable to typical chain branching reactions involving $\mathrm{HO}_{2}{ }^{\bullet}$.

\section{Methodology}

\subsection{Selection of the Model Compounds}

Both anilines and phenols are suitable candidates for study. Although anilines display far superior effect on RON compared with phenols, the presence of nitrogen in anilines will result in the formation of $\mathrm{NO}_{x}$. Therefore, oxygenated hydrocarbon additives are preferred over nitrogenated analogues. The methodology described herein is equally applicable to anilines. Twelve phenols were selected for testing as model compounds (Figure 2).

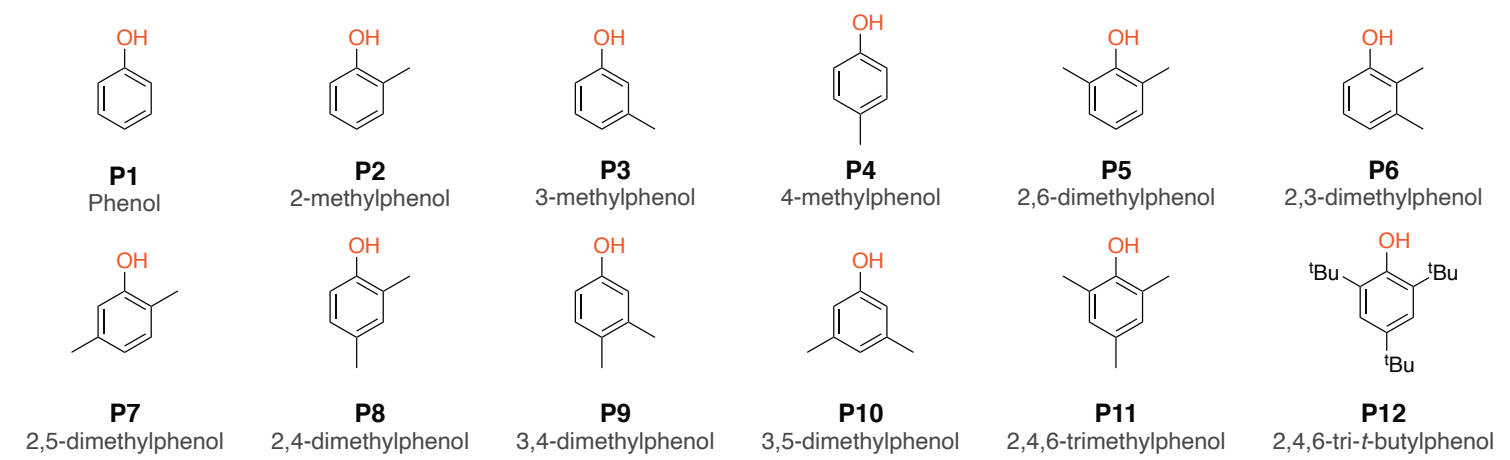

Figure 2. The chemical structures of the 12 phenols tested as anti-knock additives as part of this work.

This family of compounds was selected to contain methodical structural variations to perturb both their efficacy as anti-knock additives and the thermodynamic and kinetic physical quantities.

\subsection{Additive Design by Molecular Thermodynamics from Theory}

Reactions 7-9 were taken as a mechanistic archetype by which to design non-metallic anti-knock additives—by linking each different reaction process to a molecular feature:

1. For Reactions 7 and 8 to be competitive with hydrogen abstraction from the fuel, the additive must possess hydrogen atoms that are readily abstracted, i.e., the $\mathrm{X}-\mathrm{H}$ bond dissociation energy must be as low as possible.

2. In order to be a sink for $\mathrm{HO}_{2}{ }^{\bullet}$ and $\mathrm{HO}^{\bullet}$, the formed radical $\left(\mathrm{X}^{\bullet}\right)$ must not decompose to produce active radicals at a timescale comparable to its rate of formation, i.e., the rate of Reaction 9 must be low compared to the rate of Reactions 7 and 8 .

On this basis, the following molecular thermodynamic quantities pertinent to a molecule's propensity to act as an anti-knock additive were identified.

\subsubsection{Bond Dissociation Energy (BDE)}

The BDE is the enthalpy required to fully dissociate any given set of atoms by homolysis. This reflects the ease with which a hydrogen atom can be abstracted from the additive. Molecules with weaker $\mathrm{X}-\mathrm{H}$ bonds are expected to be more effective additives because the rates of Reactions 7 and 8 will be higher. In many cases, an additive possesses more than one potential abstraction site. Thus, multiple additive radical species may be formed. It is important to consider this competition, therefore BDEs must be determined for each X-H environment within the molecule.

\subsubsection{Rate of Hydrogen Atom Abstraction}

In instances where there are multiple potential $\mathrm{H}$ atom abstraction sites and the $\mathrm{X}-\mathrm{H}$ BDEs are similar, both of the competing hydrogen atom abstraction reactions must be considered. This is 
achieved through considering the rates of each reaction. The rates of hydrogen atom abstraction by $\mathrm{HO}^{\bullet}$ and $\mathrm{HO}_{2}{ }^{\bullet}$ are considered.

\subsubsection{Free Energy of Formation}

A radical species that is more stable will be less prone to decomposition according to Reaction 9. It is proposed that radicals with a low change in free energy to combustion products are more thermodynamically stable because the thermodynamic driving force for their consumption is lower. Molecules with this characteristic are expected to be better additives.

The standard (Gibbs) free energy of formation $\left(\Delta G_{f}^{0}\right)$ for the additive molecules, their corresponding radicals and products of combustion $\left(\mathrm{CO}_{2}, \mathrm{H}_{2} \mathrm{O}\right)$ are determined. These quantities (i.e., the free energy change required for the conversion of the radical to oxidized products) are combined to indicate the thermodynamic stability of the additive radicals.

\subsection{Additive Testing by Small Scale Ignition Measurements}

The current methodology for assessing anti-knock additives is to "screen" additives by determining RON [11] — this is a limiting problem; $7.5 \mathrm{~g}$ of an additive with a molecular weight of $100 \mathrm{~g} \mathrm{~mol}^{-1}$ is needed to determine its effect on the RON at a $1 \mathrm{~mol} \%$ treatment rate. For this testing to be feasible, sufficient quantities of the additive must be available commercially. Consequently, the development of novel synthetic additives is severely hindered by this requirement. Synthesis at this scale, needed to allow such trial and error screening studies, challenges viability due to financial and time costs.

The derived cetane number (DCN), measured using an ignition quality tester (IQT), has previously been proposed, and to a large extent demonstrated, as a macroscopic measure of the kinetic potential of a liquid fuel. Definite success has been demonstrated in this regard for kerosene [43] and diesel type fuels [44]. The IQT is proposed here as a means to test additives on a small scale. The IQT is a constant volume combustion device, designed to measure ignition delay time $\left(\tau_{i d}\right)$. For samples where $\tau_{i d}$ is outside of the range 3.1 to $6.5 \mathrm{~ms}$ (i.e., gasoline), the DCN is then calculated using Equation (1) [45]:

$$
\mathrm{DCN}=83.99\left[\left(\tau_{i d}-1.512\right)^{-0.658}\right]+3.547
$$

Significantly, the IQT requires only $50 \mathrm{~mL}$ of fuel per test, meaning that only $0.75 \mathrm{~g}$ of an additive with a molecular weight of $100 \mathrm{~g} \mathrm{~mol}^{-1}$ is needed to determine its effect on the DCN, at a $1 \mathrm{~mol} \%$ treatment rate. This is an order of magnitude reduction on the corresponding RON measurement. The operating conditions of the IQT are locally rich and globally lean whereas those in the CFR used to determine the RON are pre-mixed and stoichiometric. Nonetheless, there have been several recent successes in correlating RON with DCN [45-48]. We therefore utilize the IQT for the purpose of determining the extent to which anti-knock additives can perturb gasoline reactivity.

The aim of this manuscript is to demonstrate the applicability of the previously described, generic, methodology to the study of phenols as anti-knock additives.

\section{Experimental}

\subsection{Computational Methodology}

All calculations were executed in the Gaussian 09 platform [49]. The geometries of all model compounds and radicals were optimized using the CBS-QB3 methodology, which has an accuracy of $\sim 2 \mathrm{kcal} \mathrm{mol}^{-1}[50,51]$. For the computation of enthalpies of formation, the atomization method was chosen to allow a fair trade-off between computational accuracy and cost [52]. Comprehensive details of this procedure are given in the supplementary material. 


\subsection{Combustion Measurements}

A standard RON 95 base gasoline, provided by Total, was utilized for all tests (Note that the methodology reported herein is independent of the base gasoline.). Test gasoline samples were formulated to contain 1 mole $\%$ of the additive at an assumed gasoline molecular weight of $100 \mathrm{~g} / \mathrm{mol}$. It is essential that samples are formulated on a mole \% basis. This is because any observed anti-knock effect occurs on a per molecule basis. Formulation on a mass \% basis, results in a different number of additive molecules in each test mixture according to the molar mass of the additive. Samples were formulated gravimetrically, according to Table S1.

DCN measurements were made by CFR Engines Canada ULC using an Ignition Quality Tester (IQT), according to ASTM D6890 [53]. RON measurements were performed using a Cooperative Fuel Research (CFR) engine according to ASTM D 2699 [11].

\subsection{Calculation of $\mathrm{HO}^{\bullet}$ and $\mathrm{HO}_{2}{ }^{\bullet}$ Concentrations}

The $\mathrm{HO}^{\bullet}$ and $\mathrm{HO}_{2}{ }^{\bullet}$ concentrations necessary to calculate hydrogen atom abstraction reaction rates were obtained through computational simulations according to Howard et al. [6]. The concentrations were taken as those of $65 \%$ of the computed ignition delay time $(750 \mathrm{~K}, 25 \mathrm{bar}, \phi=1.0)$. These conditions were selected as they have been shown to give the strongest correlation between ignition delay time and RON [54]. The calculations were made using a RON 95 gasoline surrogate fuel [6]. The values of $\left[\mathrm{HO}^{\bullet}\right]$ and $\left[\mathrm{HO}_{2}{ }^{\bullet}\right]$ used are $5.70 \times 10^{-12} \mathrm{~mol} \mathrm{~cm}^{-3}$ and $1.16 \times 10^{-8} \mathrm{~mol} \mathrm{~cm}^{-3}$, respectively.

It is important to note that as the chemical composition of the fuel changes (e.g., between a petroleum gasoline and an E10 gasoline) the concentration of key radical species, i.e., $\mathrm{HO}^{\bullet}$ and $\mathrm{HO}_{2}{ }^{\bullet}$, in the radical pool will also change. Consequently, the efficacy of an additive will likely change depending on the base fuel. To reflect this, the fundamental methodology reported here is designed such that it can be readily adapted to other base fuels, i.e., fossil, alternative or biological. This is achieved by determining the concentrations of key radical species at the aforementioned conditions for the base fuel and is relatively simple provided an appropriate surrogate and detailed kinetic model are available for the base fuel.

\section{Results and Discussion}

\subsection{Effect of Phenols P1-P12 on DCN and RON}

The viability of P1-P12 as anti-knock additives was evaluated by determining both the RON and DCN for each of the 12 additive treated gasolines as defined in Table S1. The results of these experiments are reported as the perturbation of the RON and DCN values from those of the base gasoline, i.e., $\triangle \mathrm{RON}$ and $\triangle \mathrm{DCN}$ (Table 1), which were 95 and 18.9, respectively.

An additive that effects an increase in RON is expected to decrease the DCN [45,47]. In general, this trend is observed across the measured data (Table 1, Figure 3). All of the phenols tested perturb both the RON and DCN, with the exception of P12-which only perturbs the DCN. Notable contradictions to this are $\mathrm{P} 3$ and $\mathrm{P} 6$, which display a significant $\triangle \mathrm{RON}$ ( 0.80 and 0.70 , respectively) but show small, positive values for $\triangle \mathrm{DCN}$.

The best performing additives among those tested are P11 and P8 (Figure 2). P11 gave the largest $\triangle \mathrm{DCN}$ and second largest $\triangle \mathrm{RON}$ of all the additives tested, -0.23 and 1.05 , respectively. This good performance is easily rationalized using the mechanistic considerations outlined in Section 2.2. P11 has the weakest X-H bond of the tested additives $\left(81.3 \mathrm{kcal} \mathrm{mol}^{-1}\right)$ and consequently the rate of hydrogen atom abstraction from this position by $\mathrm{HO}^{\bullet}$ and $\mathrm{HO}_{2}{ }^{\bullet}, \mathrm{K}_{\mathrm{OH}}$, is the highest among the model compounds, $12.63 \mathrm{~s}^{-1}$. Thus, the stable O-centered radical will be formed quicker for P11 than for any of the other additives, i.e., P11 is the most competitive additive with Reactions 7 and 8. The presence of methyl groups in the 2-, 4-, and 6- positions is expected to inductively stabilize the resulting radical species $[37,55]$. In addition to the weak X-H bond, P11 also contains the highest number of instances of methyl C-H bonds, with 9 in total. This is reflected in the highest branching 
fraction, 0.86. Consequently, $\mathrm{P} 11$ has a significantly higher rate of abstraction at the $\mathrm{CH}_{3}$ position. Abstraction of an $\mathrm{H}$ atom from the methyl group will also sequester $\mathrm{HO}^{\bullet}$ and $\mathrm{HO}_{2}{ }^{\bullet}$, as shown by Zhang [42]. A definitive conclusion of which of these two competing mechanisms is most significant in inhibiting knock cannot be drawn from the data presented here; further experiments are necessary.

Table 1. Experimental and fundamental molecular thermodynamic anti-knock parameters of the model compounds, where $\mathrm{K}$ is the reaction rate and $\mathrm{K}_{\mathrm{B}}$ the branching fraction.

\begin{tabular}{|c|c|c|c|c|c|c|c|c|c|}
\hline \multirow{2}{*}{ Model Compound } & \multirow{2}{*}{$\triangle \mathrm{RON}$} & \multirow{2}{*}{$\triangle \mathrm{DCN}$} & $\mathrm{BDE}_{\mathrm{OH}}$ & $\mathrm{BDE}_{\mathrm{CH}_{3}}$ & $\mathrm{~K}_{\mathrm{OH}}$ & $\mathrm{K}_{\mathrm{CH}_{3}}$ & \multirow{2}{*}{$\mathbf{K}_{\mathbf{B}}$} & $\Delta \mathbf{G}_{\text {Tot }}$ & \multirow{2}{*}{$\# \mathrm{CH}_{3}$} \\
\hline & & & \multicolumn{2}{|c|}{ kcal mol $^{-1}$} & \multicolumn{2}{|c|}{$\mathrm{s}^{-1}$} & & scal mol $^{-1}$ & \\
\hline P1 & 0.15 & 0.28 & 87.09 & $\mathrm{n} / \mathrm{a}$ & 10.33 & $\mathrm{n} / \mathrm{a}$ & 0.31 & -472.8 & 0 \\
\hline P2 & 0.40 & -0.01 & 85.30 & 90.60 & 11.04 & 25.63 & 0.73 & -432.0 & 1 \\
\hline P3 & 0.80 & 0.07 & 87.00 & 91.00 & 10.37 & 25.20 & 0.74 & -432.4 & 0 \\
\hline P4 & 1.00 & -0.11 & 84.70 & 89.90 & 11.28 & 26.49 & 0.73 & -432.4 & 1 \\
\hline P5 & 0.60 & -0.06 & 83.50 & 90.80 & 11.76 & 50.89 & 0.82 & -409.8 & 2 \\
\hline P6 & 0.80 & 0.11 & 85.40 & 89.90 & 11.01 & 52.81 & 0.84 & -410.1 & 1 \\
\hline P7 & 1.05 & -0.17 & 83.40 & 90.70 & 11.80 & 51.98 & 0.83 & -409.8 & 1 \\
\hline P8 & 1.20 & -0.14 & 83.10 & 90.60 & 11.92 & 51.40 & 0.82 & -409.9 & 2 \\
\hline P9 & 0.70 & -0.11 & 85.00 & 90.50 & 11.16 & 51.56 & 0.83 & -410.4 & 1 \\
\hline P10 & 0.80 & 0.11 & 87.00 & 91.10 & 10.37 & 50.19 & 0.84 & -410.0 & 0 \\
\hline P11 & 1.05 & -0.23 & 81.30 & 90.30 & 12.63 & 78.03 & 0.86 & -396.0 & 3 \\
\hline P12 & 0.00 & 0.98 & $\mathrm{n} / \mathrm{a}$ & $\mathrm{n} / \mathrm{a}$ & $\mathrm{n} / \mathrm{a}$ & $\mathrm{n} / \mathrm{a}$ & $\mathrm{n} / \mathrm{a}$ & $\mathrm{n} / \mathrm{a}$ & $\mathrm{n} / \mathrm{a}$ \\
\hline
\end{tabular}

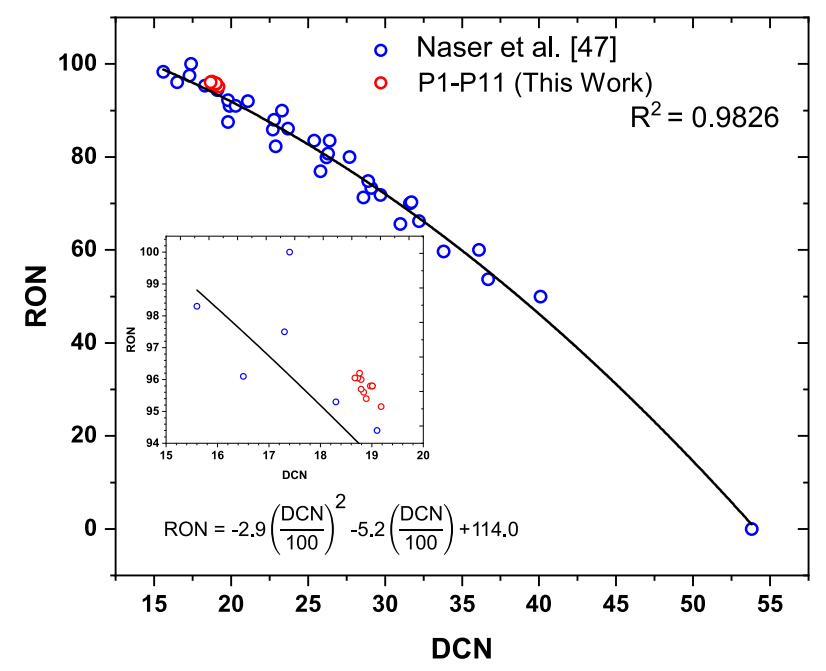

Figure 3. Comparison of the Derived Cetane Number $(\mathrm{DCN})$ to research octane number (RON) correlation from Naser et al. [47] (blue) and this work (red). From this work, the RON was measured according to ASTM D699 and the DCN was measured using ASTM D6890 for a RON = 95, DCN = 18.9 gasoline treated with 1 mole \% of phenol model compounds P1-P12 (Table S1). Inset: Shows an expansion of the DCN and RON regions tested in this work.

P8 showed the highest measured $\triangle \mathrm{RON}, 1.20$, and a modest $\triangle \mathrm{DCN}$ of -0.14 . Here, comparisons can be drawn between the other molecular thermodynamic properties for the other di-methyl phenols (P5-P10) in Table 1. P8 has the lowest O-H BDE of the di-methyl phenols $\left(83.10 \mathrm{kcal} \mathrm{mol}^{-1}\right)$ and consequently the highest rate of abstraction at $\mathrm{OH}\left(11.92 \mathrm{~s}^{-1}\right)$. However, this difference alone is not significant enough to account for the observed variations in reactivity, e.g., $\mathrm{P} 8(\triangle \mathrm{RON}=1.20$, $\Delta \mathrm{DCN}=-0.14)$ vs. $\mathrm{P} 5(\triangle \mathrm{RON}=0.6, \Delta \mathrm{DCN}=0.06)$. In this instance, it is possible that kinetic factors 
not taken into consideration here play an important role. For example, the two methyl groups adjacent to the $\mathrm{OH}$ in $\mathrm{P} 5$ sterically limit access to the $\mathrm{O}-\mathrm{H}$ bond.

A $\triangle \mathrm{DCN}$ of +0.98 was obtained for P12. This is a result of the t-butyl groups, which allow for unimolecular decomposition of the C-centered radical by $\beta$-scission and release a methyl radical; accelerating the ignition process [37]. This result offers an important design rule for anti-knock additives: no scissionable single bonds should be included at locations $\beta$ to any radical site. The large $\triangle \mathrm{DCN}$ is not reflected in the $\triangle \mathrm{RON}$, which was zero (Table 1). It is not possible to draw any further meaningful conclusions from this anomaly without further experiments to test a wider range of samples.

The purpose of measuring both RON and DCN for each test fuel was to establish the validity of the RON to DCN correlation, as has been reported elsewhere [45-48], to the testing of anti-knock additives. The results of these experiments are given in Figure 3, alongside those of Naser et al.

The correlation between the DCN and RON measured for the phenol treated gasolines in this work is in excellent agreement with that reported by Naser [47]. $R^{2}$ for both datasets combined is 0.9826 (Figure 3), over the full DCN/ RON range of data. This demonstrates the validity and utility of small-scale ignition measurements using the IQT in assessing the efficacy of fuel additives, in this case phenols. The DCN/RON region encountered in this work, i.e., $\mathrm{RON}>\sim 95, \mathrm{DCN}<\sim 20$ is shown in the inset of Figure 2. In this region, the correlation is notably weaker than that observed over the whole DCN/RON range. Importantly, however, this does not affect the conclusions drawn above regarding the utility of the DCN measurements for assessing anti-knock additives. It should be expected that a systematic study of DCN and RON in this specific region would lead to a significant improvement in the observed correlation.

It is important to note that the DCN measurements used to establish this correlation in both this work and that of Naser were made according to ASTM D6890. These test conditions were established to relate the IQT measured ignition delay to cetane number for fuels in the ignition quality range of diesel fuels. It is therefore essential to realize that the ASTM D 6890 IQT test condition is in no way optimized or designed to reflect $\mathrm{ON}$ ignition characters, nor gasoline ignition quality. This would be very desirable, and we believe is certainly possible. Toward this purpose, Singh and co-workers have used 0-d ignition delay simulations to demonstrate the correlation of ignition delay with both RON and MON [54]. It was shown that ignition delay times calculated at $750 \mathrm{~K}$ and 25 bar gave the strongest correlation to RON, while ignition delay times calculated at $825 \mathrm{~K}$ and 25 bar gave the optimum correlation for MON. For comparison, DCN is measured at approximately $833 \mathrm{~K}$ and 22.1 bar [43]. Whereas, Dooley and Won have shown that DCN indicated a different temperature mark of homogeneous ignition reactivity [43]. This comparison indicates that the operating conditions of the IQT could be adjusted to either higher or lower reaction temperatures from those of ASTM D 6890 in order to better reflect $\mathrm{ON}$ ignition character, and could perhaps be optimized further to best correlate the measurable ignition delay time with $\mathrm{RON}$ and MON.

\subsection{Calculation of Molecular Thermodynamic Properties Relative to Knock}

Detailed chemical kinetic models require development over many years to be completed for a comprehensive range of conditions. Therefore, detailed models are not suitable for the high throughput design-testing strategy described here. BDE and free energy of formation are molecular thermodynamic properties that are pertinent to the mechanism of anti-knock additives proposed above and crucially, are computationally inexpensive and readily determinable. Here, these quantities are used to derive additional useful thermodynamic properties for anti-knock additives to be incorporated into numerical models.

\subsubsection{Determination of the Rate of Hydrogen Atom Abstraction by $\mathrm{HO}^{\bullet}$ and $\mathrm{HO}_{2}{ }^{\bullet}$}

Determination of reaction rates is computationally expensive. Therefore, the rate of abstraction by $\mathrm{HO}^{\bullet}$ and $\mathrm{HO}_{2}{ }^{\bullet}$ with each X-H position were estimated by correlation of the BDE of the known $\mathrm{CH}$ 
bonds to known reaction rate constants on a per hydrogen atom basis at $800 \mathrm{~K}$ [56-58]. The resulting plots were fitted linearly (Figure S1) and the rate constants for the model compounds were extrapolated (Table S2). These rate constants were converted to reaction rate with the computed concentrations of $\mathrm{HO}^{\bullet}$ and $\mathrm{HO}_{2}{ }^{\bullet}$ described above. The total rate at each site was calculated as the sum of the rates of reaction with $\mathrm{HO}^{\bullet}$ and $\mathrm{HO}_{2}{ }^{\bullet}$, to give an overall rate of reaction at the $\mathrm{O}-\mathrm{H}\left(\mathrm{K}_{\mathrm{OH}}\right)$, methyl C- $\mathrm{H}\left(\mathrm{K}_{\mathrm{CH}_{3}}\right)$ (Table 1), and aromatic $\mathrm{C}-\mathrm{H}$ positions $\left(\mathrm{K}_{\mathrm{CH}}\right)$ (Table $\mathrm{S} 2$ ).

Although the $\mathrm{O}-\mathrm{H}$ bond is always weaker than the methyl C-H bonds, the greater number of methyl C-H bonds in P2-P11 results in a dominance of abstraction from the methyl positions. Note that the aromatic $\mathrm{C}-\mathrm{H}$ bond is significantly stronger than both $\mathrm{O}-\mathrm{H}$ and methyl $\mathrm{C}-\mathrm{H}$ bonds; therefore, abstraction from the aromatic $\mathrm{C}-\mathrm{H}$ positions is never competitive and thus not considered.

Abstraction at the $\mathrm{OH}$ position yields a more stable radical as the resulting phenoxyl radical can be inductively stabilized by any adjacent methyl groups. Conversely, the stability of the benzyl radical formed by abstraction at the $\mathrm{CH}_{3}$ positions is reduced due to the electron withdrawing effect of the $\mathrm{OH}$ group [59]. This is reflected in the higher free energies observed for the $\mathrm{C}$-centered radicals compared to the O-centered radicals (Table S2). Abstraction at the $\mathrm{CH}$ position is not favorable as the phenyl radical is not resonance stabilized. Thus, the benzyl and phenyl radicals are considered more reactive than the phenoxyl radical. To reflect this, a branching ratio $\left(K_{B}\right)$ was calculated (Table 1$)$ as

$$
K_{B}=\frac{K_{\mathrm{CH}_{3}}+K_{\mathrm{CH}}}{K_{\mathrm{OH}}+K_{\mathrm{CH}_{3}}+K_{\mathrm{CH}}}
$$

\subsubsection{Gibbs Free Energy Terms}

The Gibbs free energy of formation for both $\mathrm{O}$ and methyl centered radicals (Table S1) was used to determine the free energy of reaction from the complete combustion of the radical:

$$
\begin{gathered}
x^{\bullet}+\mathrm{O}_{2} \longrightarrow \mathrm{xCO}_{2}+\mathrm{yH}_{2} \mathrm{O} \\
\Delta \mathrm{G}_{\mathrm{R} \times \mathrm{n}}=\mathrm{xG}_{\mathrm{CO}_{2}}+\mathrm{yG}_{\mathrm{H}_{2} \mathrm{O}}-\mathrm{G}_{\text {radical }}
\end{gathered}
$$

This is indicative of the thermodynamic driving force for the consumption of the radical (Note: $\mathrm{G}_{\text {radical }}$ is the mean $\mathrm{G}$ for the $\mathrm{O}$ and C-centered radicals, Table S3). The values of $\mathrm{x}$ and $\mathrm{y}$ in Equation (3) differ depending on the empirical formula of the radical. Radicals with a higher number of carbon atoms will produce more moles of $\mathrm{CO}_{2}$ per mole of radical. The Gibbs free energy of reaction (Equation (3)) will be scaled accordingly. Thus, the Gibbs free energy of reaction for the model compounds are not directly comparable with one another. Therefore, the Gibbs free energy of reaction was normalized according to the values of $\mathrm{x}$ and $\mathrm{y}$ as follows.

$$
\Delta G_{T o t}=\frac{\Delta G_{R x n}}{x}+\frac{\Delta G_{R x n}}{y}
$$

$\Delta \mathrm{G}_{\mathrm{Tot}}$ is representative of the thermodynamic stability of the radical, i.e., the driving force for its decomposition. A radical with a lower magnitude $\Delta \mathrm{G}_{\text {Tot }}$ is hypothesized to be a more effective additive.

\subsubsection{Number of Alkyl Substituents $\left(\# \mathrm{CH}_{3}\right)$}

Additives that form more stable radical species are expected to have a greater influence as anti-knock additives. Electron donating alkyl substituents in the 2-, 4-, or 6-positions on the aromatic ring are known to increase the stability of the corresponding phenoxyl radical through the inductive effect [55]. This is exemplified by the measured effect on RON and DCN of P11 and P8 discussed above. Thus, the number of substituents in these positions is used as a proxy for radical stability. 


\section{Numerical Models}

The relationship between experimental and molecular thermodynamic parameters proposed as indicators of the anti-knock propensity of an additive was investigated with multiple linear regression. The purpose of this procedure is twofold. First, and most importantly, it aids the identification of important chemical structural, thermodynamic and kinetic quantities in relation to anti-knock additives. Second, it demonstrates how these quantities may be combined to formulate a model that is predictive. Both factors can be used to inform the design and testing of the next generation of anti-knock additives by a basic science, fundamental knowledge-based approach.

Two models were developed using the data presented in Table 2. Each model was formulated such that it contained terms representative of the additive's ability to affect the proposed mechanism of knock inhibition discussed above. These two models were trained to both DCN and RON for comparative purposes.

Table 2. Summary of Models 1 and 2, trained to $\triangle \mathrm{DCN}$.

\begin{tabular}{ccccccc}
\hline \multicolumn{3}{c}{ Model 1 } & \multicolumn{3}{c}{ Model 2 } \\
\hline \multicolumn{2}{c}{$\mathbf{a}_{\mathbf{0}}+\mathbf{a}_{\mathbf{1}} \mathbf{K}_{\mathrm{CH}_{3}}+\mathbf{a}_{\mathbf{2}} \mathbf{K}_{\mathrm{OH}}+\mathbf{a}_{3} \Delta \mathbf{G}_{\mathbf{T o t}}+\mathbf{a}_{\mathbf{4}} \# \mathrm{CH}_{3}$} & \multicolumn{2}{c}{$\mathbf{a}_{\mathbf{0}}+\mathbf{a}_{\mathbf{1}} \mathbf{K}_{\mathbf{B}}+\mathbf{a}_{\mathbf{2}} \Delta \mathbf{G}_{\mathbf{T o t}}+\mathbf{a}_{3} \# \mathrm{CH}_{3}$} \\
\hline & Estimate & $\sigma_{\text {Est }}$ & $p$-Value & Estimate & $\sigma_{\text {Est }}$ & $p$-Value \\
\hline $\mathrm{a}_{0}$ & -0.724 & 2.056 & 0.737 & 3.002 & 3.174 & 0.376 \\
$\mathrm{a}_{1}$ & 0.008 & 0.004 & 0.117 & -0.982 & 0.744 & 0.228 \\
$\mathrm{a}_{2}$ & -0.293 & 0.093 & 0.020 & 0.005 & 0.006 & 0.434 \\
$\mathrm{a}_{3}$ & -0.008 & 0.004 & 0.069 & -0.114 & 0.046 & 0.041 \\
$\mathrm{a}_{4}$ & 0.090 & 0.072 & 0.262 & & & \\
\hline
\end{tabular}

In Model 1, $\mathrm{K}_{\mathrm{CH}_{3}}$ and $\mathrm{K}_{\mathrm{OH}}$ were included to indicate the rate of formation of each radical species, $\Delta \mathrm{G}_{\mathrm{Tot}}$ to indicate the thermodynamic driving force for the decomposition of the radicals, and $\# \mathrm{CH}_{3}$ to indicate the likely reactivity of the O-centered radical. The resulting model fits the training data well (Table 2), with $\mathrm{R}^{2}=0.8954$ when trained to DCN (Figure 4). However, the analogous model for RON (Model 3) shows a significantly worse fit to the training data (Table 3), with $\mathrm{R}^{2}=0.6487$. This may be attributed to the DCN and RON tests being performed under significantly different operating conditions. Therefore, it might be inferred that the behavior of the additive under the different conditions has different dependencies on the thermodynamic and kinetic constants. It may be possible to reduce this discrepancy by optimizing the conditions under which DCN is determined for the purpose of evaluating the anti-knock effect of gasoline additives such that they are more comparable with RON measurements.

Models 2 and 4 (Tables 2 and 3 ) were formulated to include the branching ratio, $\mathrm{K}_{\mathrm{B}}$, as a more physico-chemically significant predictor (see above). However, both models give a significantly worse fit, $R^{2}=0.7345$ and 0.5323 of the training data compared to Model 1 (Figure 4). This could be attributed to the branching ratio being fundamentally correlated to the number of methyl groups present in the molecule. For methyl-substituted phenols, a greater number of methyl groups can lead to both improved inductive stabilization of the radical center and a larger branching ratio. These effects are postulated to have opposite influences on the anti-knock effect of the additive. For example, P11 shows the largest $\triangle \mathrm{DCN}$. The free energy of the resulting O-radical (Table S2) indicates that it is the most stable out of all of the compounds tested. However, P11 also has the largest branching ratio. The relative influence of these quantities cannot be distinguished by Models 2 and 4 . Thus, for Models 2 and 4 , inclusion of $K_{B}$ decreases the quality of the fit compared to Model 1. 
Table 3. Summary of Models 3 and 4, trained to $\triangle \mathrm{RON}$.

\begin{tabular}{ccccccc}
\hline & \multicolumn{3}{c}{ Model 3 } & \multicolumn{3}{c}{ Model 4 } \\
\hline \multicolumn{2}{c}{$\mathbf{a}_{\mathbf{0}}+\mathbf{a}_{\mathbf{1}} \mathbf{K}_{\mathrm{CH}_{3}}+\mathbf{a}_{\mathbf{2}} \mathrm{K}_{\mathrm{OH}}+\mathbf{a}_{3} \Delta \mathbf{G}_{\mathrm{Tot}}+\mathbf{a}_{4} \# \mathrm{CH}_{3}$} & \multicolumn{2}{c}{$\mathbf{a}_{\mathbf{0}}+\mathbf{a}_{\mathbf{1}} \mathbf{K}_{\mathbf{B}}+\mathbf{a}_{2} \Delta \mathbf{G}_{\mathrm{Tot}}+\mathbf{a}_{3} \# \mathrm{CH}_{3}$} \\
\hline & Estimate & $\sigma_{\text {Est }}$ & $p$-Value & Estimate & $\sigma_{\text {Est }}$ & $p$-Value \\
\hline $\mathrm{a}_{0}$ & 1.666 & 7.655 & 0.835 & -0.054 & 8.557 & 0.995 \\
$\mathrm{a}_{1}$ & -0.007 & 0.016 & 0.679 & 1.220 & 2.006 & 0.562 \\
$\mathrm{a}_{2}$ & 0.518 & 0.345 & 0.184 & 0.000 & 0.017 & 0.984 \\
$\mathrm{a}_{3}$ & 0.014 & 0.014 & 0.352 & 0.049 & 0.123 & 0.700 \\
$\mathrm{a}_{4}$ & -0.323 & 0.269 & 0.275 & & & \\
\hline
\end{tabular}

The results obtained from the multiple linear regression analysis demonstrate that carefully identified and determined thermodynamic and kinetic quantities can be used as predictors for the anti-knock effect of a gasoline additive.
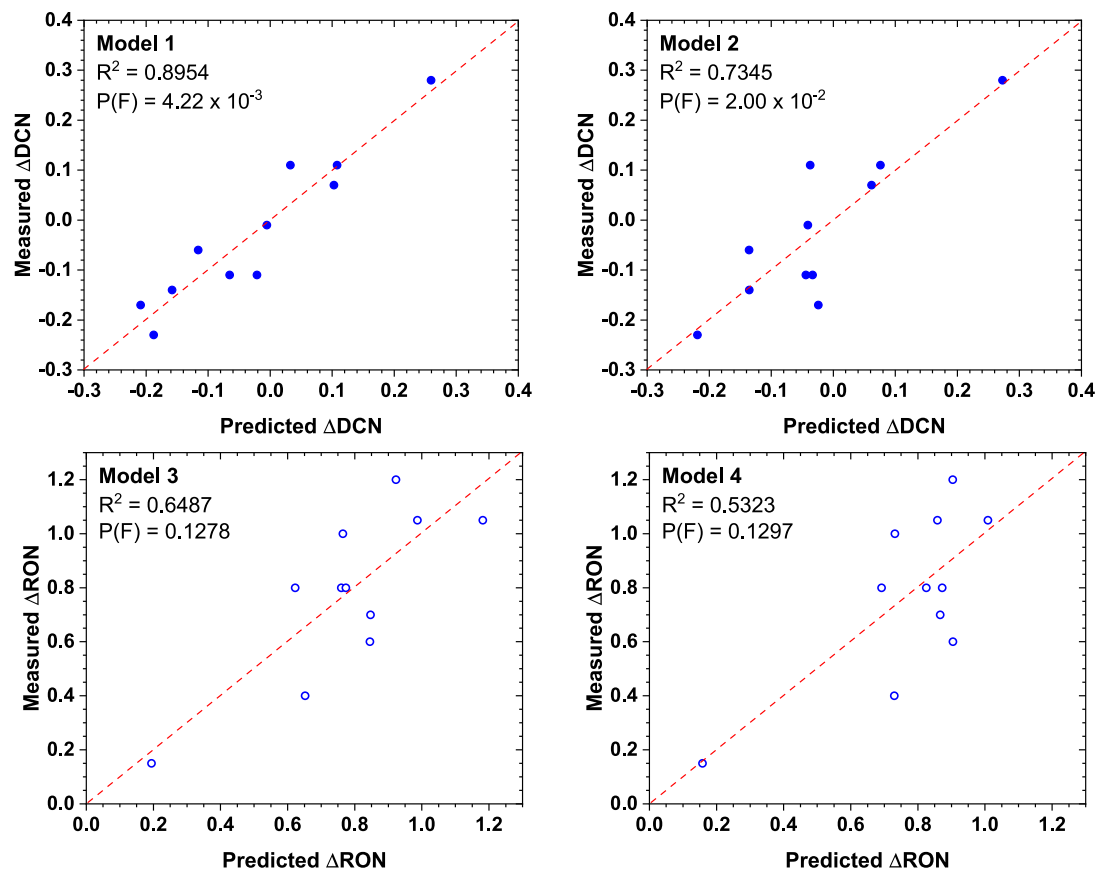

Figure 4. Predicted vs. measured DCN and RON for the models described in Tables 2 and 3.

\section{Conclusions}

Since the discovery of tetra ethyl lead as an anti-knock additive in 1922, the brute force screening approach adopted towards its identification has remained the prominent research strategy towards the identification of new anti-knock additives. This approach is used despite the very significant advancements in our knowledge of knock, combustion kinetics, and theoretical chemical kinetics, including computational methodologies for determining molecular thermodynamic quantities at our disposal in the intervening century. This contribution proposes an innovative, generic and educated methodology by which the next generation of anti-knock additives may be identified. Built in to the methodology is a strategy for anti-knock additive design, synthesis and testing at the few-gram scale.

The mechanisms by which anti-knock additives are proposed to operate were carefully considered to determine key reaction pathways with which a successful anti-knock additive should interfere. Design criteria for a successful anti-knock additive were outlined. The additive should contain a 
weak X-H bond such that it reacts quickly with $\mathrm{HO}^{\bullet} / \mathrm{HO}_{2} \bullet$ and form a stable radical after hydrogen atom abstraction. On this basis, generic chemical structural, kinetic, and thermodynamic quantities that reflect the ability of a molecule to act as an anti-knock additive were identified and determined from theory.

The IQT was identified as an experimental platform by which the efficacy of anti-knock additives can be tested on one tenth of the scale of the current CFR-based methods. Importantly, this opens the way for new additives to be designed, synthesized and tested on a time and cost scale that is significantly more viable than prior art.

The experimental measurements were modeled using molecular thermodynamic quantities derived from theory by multiple linear regression analyses; the correlation observed between these parameters in Model 1 demonstrates the potential predictive capacity offered by this methodology and offers a clear route to a more refined basic science knowledge-based approach to the identification of the next generation of not only anti-knock additives, but additives in general.

Supplementary Materials: The following are available online at http:/ / www.mdpi.com/1996-1073/13/18/4923/ s1, Table S1: Formulation of the fuel samples used to measure DCN, containing phenols P1-P12, Table S2: Thermodynamic and kinetic data for the additives studied, Table S3: Calculation of $\mathrm{G}_{\mathrm{Tot}}$. Average $\mathrm{G}$ radical was calculated as a weighted average of the $\mathrm{O}$ and $\mathrm{C}$-centered radicals based on the radical populations. Figure S1: title, Correlation of BDE to rate constant for hydrogen atom abstraction at $800 \mathrm{~K}$.

Author Contributions: Conceptualization, A.D.U., M.K.G., and S.D.; computational calculations, M.K.G.; sample preparation, A.D.U.; numerical analysis, A.D.U.; writing-original draft preparation, A.D.U.; writing-review and editing, M.G., S.D., M.R., and R.D.; project administration, A.D.U., S.D., and R.D.; funding acquisition, S.D. All authors have read and agreed to the published version of the manuscript.

Funding: This work was supported by TOTAL Marketing Services and Science Foundation Ireland under awards 16/ERCD/3685 and 13/SIRG/2185.

Acknowledgments: IQT measurements were performed by CFR Canada ULC. Computational resources were provided by the Irish Centre for High-End Computing, ICHEC.

Conflicts of Interest: The authors declare no conflicts of interest.

\section{References}

1. Splitter, D.; Pawlowski, A.; Wagner, R. A Historical Analysis of the Co-evolution of Gasoline Octane Number and Spark-Ignition Engines. Front. Mech. Eng. 2016, 1, 16. [CrossRef]

2. European Commission. Commission Regulation (EU) No 459/2012 of 29 May 2012 Amending Regulation (EC) No 715/2007 of the European Parliament and of the Council and Commission Regulation (EC) No 692/2008 as Regards Emissions from Light Passenger and Commercial Vehicles (Euro 6); European Commission: Brussels, Belgium, 2012.

3. Directive (EU) 2018/2001 of the European Parliament and of the Council of 11 December 2018 on the Promotion of the Use of Energy from Renewable Sources. Available online: http://eur-lex.europa.eu/ (accessed on 5 June 2020).

4. Ribeiro, N.M.; Pinto, A.C.; Quintella, C.M.; da Rocha, G.O.; Teixeira, L.S.G.; Guarieiro, L.L.N.; do Carmo Rangel, M.; Veloso, M.C.C.; Rezende, M.J.C.; Serpa da Cruz, R.; et al. The Role of Additives for Diesel and Diesel Blended (Ethanol or Biodiesel) Fuels: A Review. Energy Fuels 2007, 21, 2433-2445. [CrossRef]

5. Speth, R.L.; Chow, E.W.; Malina, R.; Barrett, S.R.H.; Heywood, J.B.; Green, W.H. Economic and Environmental Benefits of Higher-Octane Gasoline. Environ. Sci. Technol. 2014, 48, 6561-6568. [CrossRef] [PubMed]

6. Howard, M.S.; Issayev, G.; Naser, N.; Sarathy, S.M.; Farooq, A.; Dooley, S. Ethanolic gasoline, a lignocellulosic advanced biofuel. Sustain. Energy Fuels 2019, 3, 409-421. [CrossRef]

7. Seyferth, D. The Rise and Fall of Tetraethyllead. 2. Organometallics 2003, 22, 5154-5178. [CrossRef]

8. Wang, Z.; Liu, H.; Reitz, R.D. Knocking combustion in spark-ignition engines. Prog. Energy Combust. Sci. 2017, 61, 78-112. [CrossRef]

9. Westbrook, C.K. Chemical kinetics of hydrocarbon ignition in practical combustion systems. Proc. Combust. Inst. 2000, 28, 1563-1577. [CrossRef] 
10. Kalghatgi, G.T. Developments in internal combustion engines and implications for combustion science and future transport fuels. Proc. Combust. Inst. 2015, 35, 101-115. [CrossRef]

11. ASTM International. ASTM D2699-18, Standard Test Method for Research Octane Number of Spark-Ignition Engine Fuel; ASTM International: West Conshohocken, PA, USA, 2018. [CrossRef]

12. Westbrook, C.K.; Warnatz, J.; Pitz, W.J. A detailed chemical kinetic reaction mechanism for the oxidation of iso-octane and $n$-heptane over an extended temperature range and its application to analysis of engine knock. Symp. (Int.) Combust. 1989, 22, 893-901. [CrossRef]

13. Brown, J.E.; Lovell, W.G. A New Manganese Antiknock. Ind. Eng. Chem. 1958, 50, 1547-1550. [CrossRef]

14. Fenard, Y.; Song, H.; Dauphin, R.; Vanhove, G. An engine-relevant kinetic investigation into the anti-knock effect of organometallics through the example of ferrocene. Proc. Combust. Inst. 2019, 37, 547-554. [CrossRef]

15. Bradley, D.; Morley, C. Chapter 7 Autoignition in spark-ignition engines. In Comprehensive Chemical Kinetics; Pilling, M.J., Ed.; Elsevier: Amsterdam, The Netherlands, 1997; Volume 35, pp. 661-760. [CrossRef]

16. Ballinger, P.R.; Ryason, P.R. Isolated stable cool flames of hydrocarbons. Symp. (Int.) Combust. 1971, 13, 271-277. [CrossRef]

17. Erhard, K.H.L.; Norrish, R.G.W. Studies of knock and antiknock by kinetic spectroscopy. Proc. R. Soc. Lond. Ser. Math. Phys. Sci. 1956, 234, 178-191. [CrossRef]

18. Erhard, K.H.L.; Norrish, R.G.W. Studies of knock and antiknock by kinetic spectroscopy. II. Proc. R. Soc. Lond. Ser. Math. Phys. Sci. 1960, 259, 297-303. [CrossRef]

19. Benson, S.W. The mechanism of inhibition of knock by lead additives, a chain debranching reaction. J. Phys. Chem. 1988, 92, 1531-1533. [CrossRef]

20. Chamberlain, G.H.N.; Walsh, A.D.; Egerton, A.C. The inhibiting effect of lead tetraethyl I. The effect of lead compounds on the vapour phase slow oxidation of diisopropyl ether and on the ignition of diethyl ether. Proc. R. Soc. Lond. Ser. Math. Phys. Sci. 1952, 215, 175-186. [CrossRef]

21. Hoare, D.E.; Walsh, A.D.; Egerton, A.C. The inhibiting effect of lead tetraethyl II. The effect of lead monoxide on the slow oxidation of methane. Proc. R. Soc. Lond. Ser. Math. Phys. Sci. 1952, 215, 454-466. [CrossRef]

22. Salooja, K.C. Studies relating to the mechanism of antiknock action of tetraethyl lead. Combust. Flame 1965, 9, 211-217. [CrossRef]

23. Salooja, K.C. Studies of combustion processes leading to ignition in hydrocarbons. Combust. Flame 1960, 4, 117-136. [CrossRef]

24. Pahnke, A.J.; Cohen, P.M.; Sturgis, B.M. Preflame Oxidation of Hydrocarbons in a Motored Engine. Ind. Eng. Chem. 1954, 46, 1024-1029. [CrossRef]

25. Walsh, A.D. Knock In Internal Combustion Engines and the Anti-Knock Effect of Lead Tetra Ethyl. J. R. Inst. Chem. 1951, 75, 319-371. [CrossRef]

26. Cheaney, D.E.; Davies, D.A.; Davis, A.; Hoare, D.E.; Protheroe, J.; Walsh, A.D. Effects of surfaces on combustion of methane and mode of action of anti-knocks containing metals. Symp. (Int.) Combust. 1958, 7, 183-187. [CrossRef]

27. Graiff, L.B. The Mode of Action of Tetraethyllead and Supplemental Antiknock Agents; SAE Transactions: Warrendale, PA, USA, 1966. [CrossRef]

28. Boot, M.D.; Tian, M.; Hensen, E.J.M.; Mani Sarathy, S. Impact of fuel molecular structure on auto-ignition behavior-Design rules for future high performance gasolines. Prog. Energy Combust. Sci. 2017, 60, 1-25. [CrossRef]

29. Poulopoulos, S.; Philippopoulos, C. Influence of MTBE addition into gasoline on automotive exhaust emissions. Atmos. Environ. 2000, 34, 4781-4786. [CrossRef]

30. Brocard, J.C.; Baronnet, F.; O'Neal, H.E. Chemical kinetics of the oxidation of methyl tert-butyl ether (MTBE). Combust. Flame 1983, 52, 25-35. [CrossRef]

31. Le, Q.N.; Thomson, R.T. Process for the Production of Tertiary Alkyl Ether Rich FCC Gasoline. U.S. Patent 5,489,719, 6 February 1996.

32. Tian, M.; McCormick, R.L.; Luecke, J.; de Jong, E.; van der Waal, J.C.; van Klink, G.P.M.; Boot, M.D. Anti-knock quality of sugar derived levulinic esters and cyclic ethers. Fuel 2017, 202, 414-425. [CrossRef]

33. Christensen, E.; Williams, A.; Paul, S.; Burton, S.; McCormick, R.L. Properties and performance of levulinate esters as diesel blend components. Energy Fuels 2011, 25, 5422-5428. [CrossRef]

34. Christensen, E.; Yanowitz, J.; Ratcliff, M.; McCormick, R.L. Renewable oxygenate blending effects on gasoline properties. Energy Fuels 2011, 25, 4723-4733. [CrossRef] 
35. Heyne, J.S.; Dryer, F.L. Uncertainty analysis in the use of chemical thermometry: A case study with cyclohexene. J. Phys. Chem. A 2013, 117, 5401-5406. [CrossRef]

36. Heyne, J.S.; Dooley, S.; Dryer, F.L. Dehydration rate measurements for tertiary -butanol in a variable pressure flow reactor. J. Phys. Chem. A 2013, 117, 8997-9004. [CrossRef]

37. Walsh, A.D. The effect of aromatic compounds on the vapour-phase oxidation of fuels. Part II.The anti-knock effect of aromatic compounds in engines. Trans. Faraday Soc. 1949, 45, 1043-1048. [CrossRef]

38. Dussan, K.; Won, S.H.; Ure, A.D.; Dryer, F.L.; Dooley, S. Chemical functional group descriptor for ignition propensity of large hydrocarbon liquid fuels. Proc. Combust. Inst. 2019, 37, 5083-5093. [CrossRef]

39. Brown, J.E.; Markley, F.X.; Shapiro, H. Mechanism of Aromatic Amine Antiknock Action. Ind. Eng. Chem. 1955, 47, 2141-2146. [CrossRef]

40. Mohamed, C. Suppression of reaction during rapid compression and its effect on ignition delay. Combust. Flame 1998, 112, 438-444. [CrossRef]

41. Halstead, M.P.; Quinn, C.P. Inhibition of autoignition at high pressure. Combust. Flame 1973, 20, $223-230$. [CrossRef]

42. Zhang, P.; Yee, N.W.; Filip, S.V.; Hetrick, C.E.; Yang, B.; Green, W.H. Modeling study of the anti-knock tendency of substituted phenols as additives: An application of the reaction mechanism generator (RMG). Phys. Chem. Chem. Phys. 2018, 20, 10637-10649. [CrossRef]

43. Dooley, S.; Won, S.H.; Chaos, M.; Heyne, J.; Ju, Y.; Dryer, F.L.; Kumar, K.; Sung, C.J.; Wang, H.; Oehlschlaeger, M.A.; et al. A jet fuel surrogate formulated by real fuel properties. Combust. Flame 2010, 157, 2333-2339. [CrossRef]

44. Mueller, C.J.; Cannella, W.J.; Bays, J.T.; Bruno, T.J.; DeFabio, K.; Dettman, H.D.; Gieleciak, R.M.; Huber, M.L.; Kweon, C.B.; McConnell, S.S.; et al. Diesel Surrogate Fuels for Engine Testing and Chemical-Kinetic Modeling: Compositions and Properties. Energy Fuels 2016, 30, 1445-1461. [CrossRef]

45. Naser, N.; Sarathy, S.M.; Chung, S.H. Ignition delay time sensitivity in ignition quality tester (IQT) and its relation to octane sensitivity. Fuel 2018, 233, 412-419. [CrossRef]

46. McCormick, R.L.; Fioroni, G.; Fouts, L.; Christensen, E.; Yanowitz, J.; Polikarpov, E.; Albrecht, K.; Gaspar, D.J.; Gladden, J.; George, A. Selection Criteria and Screening of Potential Biomass-Derived Streams as Fuel Blendstocks for Advanced Spark-Ignition Engines. SAE Int. J. Fuels Lubr. 2017, 10, 442-460. [CrossRef]

47. Naser, N.; Yang, S.Y.; Kalghatgi, G.; Chung, S.H. Relating the octane numbers of fuels to ignition delay times measured in an ignition quality tester (IQT). Fuel 2017, 187, 117-127. [CrossRef]

48. Olarte, M.V.; Albrecht, K.O.; Bays, J.T.; Polikarpov, E.; Maddi, B.; Linehan, J.C.; O’Hagan, M.J.; Gaspar, D.J. Autoignition and select properties of low sample volume thermochemical mixtures from renewable sources. Fuel 2019, 238, 493-506. [CrossRef]

49. Frisch, M.; Trucks, G.W.; Schlegel, H.B.; Scuseria, G.E.; Robb, M.A.; Cheeseman, J.R.; Scalmani, G.; Barone, V.; Mennucci, B.; Petersson, G. Gaussian 09, Revision A. 02; Gaussian, Inc.: Wallingford, CT, USA, 2009.

50. Somers, K.P.; Simmie, J.M. Benchmarking Compound Methods (CBS-QB3, CBS-APNO, G3, G4, W1BD) against the Active Thermochemical Tables: Formation Enthalpies of Radicals. J. Phys. Chem. A 2015, 119, 8922-8933. [CrossRef] [PubMed]

51. Simmie, J.M.; Somers, K.P. Benchmarking Compound Methods (CBS-QB3, CBS-APNO, G3, G4, W1BD) against the Active Thermochemical Tables: A Litmus Test for Cost-Effective Molecular Formation Enthalpies. J. Phys. Chem. A 2015, 119, 7235-7246. [CrossRef] [PubMed]

52. Ghosh, M.K.; Howard, M.S.; Dooley, S. Accurate and standard thermochemistry for oxygenated hydrocarbons: A case study of ethyl levulinate. Proc. Combust. Inst. 2019, 37, 337-346. [CrossRef]

53. ASTM International. ASTM D6890-18, Standard Test Method for Determination of Ignition Delay and Derived Cetane Number (DCN) of Diesel Fuel Oils by Combustion in a Constant Volume Chamber; ASTM International: West Conshohocken, PA, USA, 2018. Available online: www.astm.org (accessed on 7 November 2019).

54. Singh, E.; Badra, J.; Mehl, M.; Sarathy, S.M. Chemical Kinetic Insights into the Octane Number and Octane Sensitivity of Gasoline Surrogate Mixtures. Energy Fuels 2017, 31, 1945-1960. [CrossRef]

55. Richard, L.S.; Bernardes, C.E.S.; Diogo, H.P.; Leal, J.P.; da Piedade, M.E. Energetics of Cresols and of Methylphenoxyl Radicals. J. Phys. Chem. A 2007, 111, 8741-8748. [CrossRef]

56. Curran, H.J.; Gaffuri, P.; Pitz, W.J.; Westbrook, C.K. A Comprehensive Modeling Study of n-Heptane Oxidation. Combust. Flame 1998, 114, 149-177. [CrossRef] 
57. Pelucchi, M.; Cavallotti, C.; Faravelli, T.; Klippenstein, S.J. H-Abstraction reactions by $\mathrm{OH}, \mathrm{HO}_{2}, \mathrm{O}_{2} \mathrm{O}_{2}$ and benzyl radical addition to $\mathrm{O}_{2}$ and their implications for kinetic modelling of toluene oxidation. Phys. Chem. Chem. Phys. 2018, 20, 10607-10627. [CrossRef]

58. Yuan, W.; Li, Y.; Pengloan, G.; Togbé, C.; Dagaut, P.; Qi, F. A comprehensive experimental and kinetic modeling study of ethylbenzene combustion. Combust. Flame 2016, 166, 255-265. [CrossRef]

59. O'Malley, P.J. Hybrid Density Functional Studies of Phenoxyl Free Radicals Modeling $\alpha$-Tocopheroxyl. J. Phys. Chem. B 2002, 106, 12331-12335. [CrossRef]

(C) 2020 by the authors. Licensee MDPI, Basel, Switzerland. This article is an open access article distributed under the terms and conditions of the Creative Commons Attribution (CC BY) license (http:/ / creativecommons.org/licenses/by/4.0/). 